\title{
Highly Selective Electrochemiluminescence Sensor Based on Molecularly Imprinted-quantum Dots for the Sensitive Detection of Cyfluthrin
}

\author{
Jinjin Xu ${ }^{1,2}$, Rongrong Zhang ${ }^{1,3}$, Chenxi Liu ${ }^{1,2}$, Aili Sun ${ }^{3}$, Jiong Chen ${ }^{1,3}$, Zeming Zhang ${ }^{1,3, *}$ \\ and Xizhi Shi $1,3, *$ \\ 1 Laboratory for Managing Biotic and Chemical Threats to the Quality and Safety of Agro-Products, \\ Ningbo University, Ningbo 315211, China; jinjinxu827@163.com (J.X.); zhangrong19910510@163.com (R.Z.); \\ 17815936495@163.com (C.L.); chenjiong@nbu.edu.cn (J.C.) \\ 2 College of Food and Pharmaceutical Sciences, Ningbo University, Ningbo 315211, China \\ 3 School of Marine Sciences, Ningbo University, Ningbo 315211, China; sunaili@nbu.edu.cn \\ * Correspondence: zhangzeming@nbu.edu.cn (Z.Z.); shixizhi@nbu.edu.cn (X.S.); \\ Tel.: +86-574-87609582 (Z.Z. \& X.S.)
}

Received: 20 December 2019; Accepted: 3 February 2020; Published: 7 February 2020

\begin{abstract}
A highly selective and sensitive molecularly imprinted electrochemiluminescence (MIECL) sensor was developed based on the multiwall carbon nanotube (MWCNT)-enhanced molecularly imprinted quantum dots (MIP-QDs) for the rapid determination of cyfluthrin (CYF). The MIP-QDs fabricated by surface grafting technique exhibited excellent selective recognition to CYF, resulting in a specific decrease of ECL signal at the MWCNT/MIP-QD modified electrode. Under optimal conditions, the MIECL signal was proportional to the logarithm of the CYF concentration in the range of $0.2 \mu \mathrm{g} / \mathrm{L}$ to $1.0 \times 10^{3} \mu \mathrm{g} / \mathrm{L}$ with a determination coefficient of 0.9983 . The detection limit of CYF was $0.05 \mu \mathrm{g} / \mathrm{L}$, and good recoveries ranging from $86.0 \%$ to $98.6 \%$ were obtained in practical samples. The proposed MIECL sensor provides a novel, rapid, high sensitivity detection strategy for successfully analyzing CYF in fish and seawater samples.
\end{abstract}

Keywords: molecularly imprinted polymers; quantum dot; cyfluthrin; electrochemiluminescence sensor; fish samples

\section{Introduction}

Cyfluthrin (CYF), a synthetic type II pyrethroid insecticide, was widely used in agricultural pest control; this insecticide could also enter aquatic ecosystems from agricultural areas via run-offs [1,2]. CYF residue was frequently detected in aquatic environments and organisms due to its widespread usage and high persistence [3,4]. Although CYF featured low mammalian toxicity, long-term exposure to this chemical caused a toxic effect on the respiratory, nervous, immune, and reproductive systems of human beings and nontarget organisms [5]. Due to these risks, various countries had stipulated their maximum CYF residues $(0.05 \mathrm{mg} / \mathrm{kg}$ in food established by China; $0.1 \mathrm{mg} / \mathrm{kg}$ in eggplant by EU; $0.01 \mathrm{mg} / \mathrm{kg}$ in farmed fish by Brazil) and banned its usage in aquaculture [6-8]. Therefore, a rapid, efficient, and sensitive method for detecting CYF residues in food and environment samples must be developed.

At present, numerous confirmatory methods including gas chromatography tandem mass spectrometry (GC-MS/MS) and liquid chromatography tandem mass spectrometry (LC-MS/MS) have been successfully applied to CYF determination [9,10]. Although these methods have shown excellent sensitivity and selectivity, they also require expensive instruments and time-consuming, sophisticated sample pretreatments, causing difficulties in saving time for unexpected food safety 
incidents; hence, these methods have been deemed unsuitable for rapid field detection [11,12]. Recently, electrochemiluminescence (ECL), also called electrogenerated chemiluminescence, attracted considerable attention from researchers due to its simpler, higher sensitivity, more precise reaction kinetics, and better controllability and reproducibility compared with other electroanalytical detection techniques [13]. ECL is a particular process in which species are triggered at electrodes by high-energy electrochemical reactions to form excited states that emit light. Furthermore, the electrochemical reactions take place between the redox products of emitters and a co-reactant, generating an excited state which might decay and emit light $[14,15]$. ECL emission was initially generated through luminol and ruthenium (II) complexes; then, increasing attention was given to nanomaterials, such as quantum dots (QDs), carbon nanodots, metal organic gels (MOGs), and noble metal clusters [16,17]. Notably, QDs possess unique optical and electronic properties, such as high quantum efficiency, photobleaching resistance, and high electron transfer efficiency, and have been widely used in ECL systems [18,19]. To further improve the specific response capability and stability of QDs, in this work we combine molecularly imprinted polymers (MIPs) with ECL analysis based on QDs, showing high selectivity and good stability and controllability [20,21]. To date, QDs and MIPs have been individually fabricated and used as signal probes and recognition elements, respectively, resulting in a complex electrode preparation procedure and a remarkably negative impact on electrical conductivity [22,23]. Therefore, to simplify the electrode preparation procedure and improve electrical conductivity in the present study, we first proposed and fabricated MIP-QDs, which were synthesized by functionalizing cadmium selenide quantum dots (CdSe QDs) with molecular imprinting polymers as both the signal probe and specific recognition element of the ECL sensor for CYF determination. Furthermore, $\mathrm{H}_{2} \mathrm{O}_{2}$ was used as a co-reactant, and multiwall carbon nanotubes (MWCNTs) were utilized as reinforcements to provide excellent electrocatalytic activity and minimize surface fouling on the electrodes. Finally, the original MIECL sensor based on the MIP-QDs for CYF determination was developed and its application capability was fully evaluated. The results indicated that the fabricated MIECL sensor-based MIP-QDs demonstrated convenient, rapid, and accurate determination of trace CYF contaminants in fish and seawater samples. To the best of our knowledge, the use of a MIECL sensor for CYF determination based on MIP-QDs, $\mathrm{H}_{2} \mathrm{O}_{2}$, and MWCNTs has yet to be reported. Scheme 1 shows the principles of the developed method.
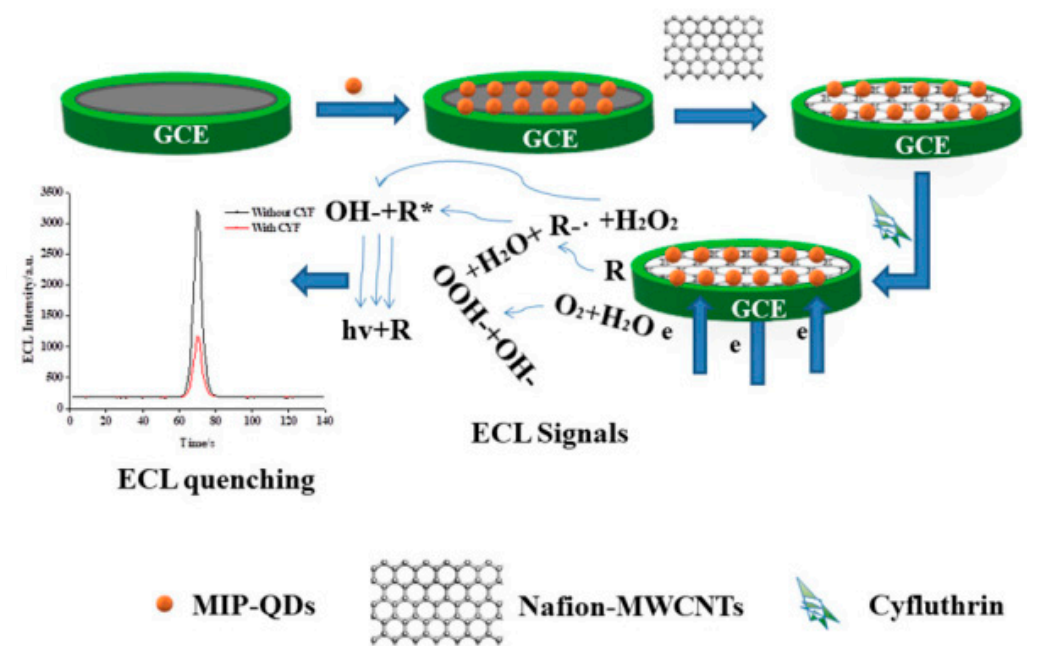

Scheme 1. Schematic representation of MIECL sensor development.

\section{Materials and Methods}

\subsection{Materials and Reagents}

CdSe QDs were purchased from BEIDA JUBANG Science \& Technology Co., Ltd. (Beijing, China). The MWCNTs were supplied by XFNANO Materials Tech Co., Ltd. (Nanjing, China). Nafion 
( $\geq 98.0 \%)$ was obtained from Sigma-Aldrich Trading Co., Ltd. (Shanghai, China). CYF, bifenthrin (BIF), deltamethrin (DEL), cypermethrin (CYP), and fenvalerate (FEN) were obtained from the Shanghai Pesticide Research Institute Co., Ltd. (Shanghai, China). 3-Aminopropyl-triethoxysilane (APTES), tetraethoxysilane (TEOS) and Triton X-100 were purchased from Sigma-Aldrich (Steinheim, Germany). $\mathrm{H}_{2} \mathrm{O}_{2}$ (AR, 30 wt. \% in $\mathrm{H}_{2} \mathrm{O}$ ) was obtained from Aladdin (Shanghai, China). All other reagents were of analytical grade and used with ultrapure water (resistivity $\geq 18.25 \Omega$ ).

\subsection{Instruments}

Cyclic voltammograms (CVs) and the corresponding ECL experiments were carried out by using an ECL analysis system (Model MPI-E; Xi'an Remax Electronic Science \& Technology Co., Ltd.; Xi'an, China). A conventional three-electrode system was used, consisting of a bare or modified glassy carbon electrode (GCE, $3 \mathrm{~mm}$ diameter), a saturated calomel electrode, and a platinum column electrode as the working, reference, and auxiliary electrodes, respectively. Electrochemical impedance spectroscopy (EIS) was investigated on an electrochemical workstation (CHI 660E; CH Instrument Company; Shanghai, China). The morphologies of the MIP-QDs and non-imprinted polymer QDs (NIP-QDs) were observed by transmission electron microscope (TEM; JEM-2100F; Hitachi Instrument; Hitachi, Japan).

\subsection{Fabrication of MIP-QDs}

The MIP-QDs were synthesized by following a modified micro-emulsion method, as previously reported in the literature [24]. Typically, $2.0 \mathrm{~mL}$ Triton-X 100 was dissolved in $8.0 \mathrm{~mL}$ cyclohexane and placed in a $50 \mathrm{~mL}$ round bottom flask. The mixture was magnetically stirred at $400 \mathrm{rpm}$ for $15 \mathrm{~min}$. Subsequently, $400.0 \mu \mathrm{L}$ CdSe QDs $(5.0 \mathrm{mg} / \mathrm{mL}), 50.0 \mu \mathrm{L}$ TEOS and $100.0 \mu \mathrm{L}$ ammonia were added in turn, and the solution was stirred for $2 \mathrm{~h}$. Then, the mixtures of $110.0 \mu \mathrm{L}$ CYF $(25.0 \mathrm{mg} / \mathrm{mL})$ and $22.8 \mu \mathrm{L}$ APTES were prepared via magnetic stirring for $2 \mathrm{~h}$ under nitrogen atmosphere and then poured into a round-bottom flask. After stirring for $12 \mathrm{~h}$, the MIP-QDs were synthesized and purified by adding $10.0 \mathrm{~mL}$ acetone to the reaction mixture, which was then centrifuged for $10 \mathrm{~min}$ at $9.0 \times 10^{3} \mathrm{~g}$. After discarding the supernatant, $6.0 \mathrm{~mL}$ ultrapure water was added and centrifuged at $9.0 \times 10^{3} \mathrm{~g}$ for $20 \mathrm{~min}$ to remove the unreacted cross-linker and functional monomer. Finally, the template was removed with ethanol in acetonitrile (4:1, v/v) until no CYF could be detected by GC-MS/MS. The non-imprinted quantum dots materials (NIP-QDs) were simultaneously synthesized in the same process without the addition of template molecules.

\subsection{Fabrication of the Nafion-MWCNTs/MIP-QDs/GCE}

Prior to modification, the GCE was polished on a mirror surface with $0.05 \mu \mathrm{m}$ alumina slurry, washed successively with absolute ethanol and ultrapure water, and ultrasonically shaken for $1 \mathrm{~min}$ to remove the polishing powder on the GCE surface. The treated bare GCE was then immersed in 100.0 $\mathrm{mmol} / \mathrm{L}$ phosphate buffer solution (PBS, pH 7.0) and scanned at a rate of $100 \mathrm{mV} / \mathrm{s}$ over the potential range of $-0.3 \mathrm{~V}$ to $0.4 \mathrm{~V}$ for five cycles. Then, the GCE was removed and ultrasonically washed in ethanol and ultrapure water to remove ions on the electrode surface. The GCE was coated with $10.0 \mu \mathrm{L}$ of the resulting MIP-QDs $(15.0 \mathrm{mg} / \mathrm{L})$ suspension solution. After evaporation, $5.0 \mu \mathrm{L}$ Nafion-MWCNTs $(2.0 \mathrm{mg} / \mathrm{L})$ solution was dropped onto the surface of the resulting MIP-QDs/GCE. Usually, Nafion is used not only as the binder to improve the adhesion of electrode sheet, but also as a mediator to facilitate the ionic transportation across the electrode [25]. After drying in air, the Nafion-MWCNTs/MIP-QDs/GCE was slightly washed with PBS $(50.0 \mathrm{mmol} / \mathrm{L})$ to remove the redundant modifier. As the control, the Nafion solution ( $0.5 \%$ mass fraction) and CdSe-QDs suspension were prepared to produce the Nafion/MIP-QDs/GCE and CdSe-QDs/GCE, respectively. Correspondingly, the NIPs with modified GCE were also fabricated under the same conditions. All modified electrodes were kept at $4{ }^{\circ} \mathrm{C}$ until use. 


\subsection{ECL Measurement}

The MIECL sensor was used in a $10.0 \mathrm{~mL}$ homemade Teflon cell. The prepared sensor adsorbed the appropriate CYF concentration for $5 \mathrm{~min}$, and CYF was then detected in $2.0 \mathrm{~mL} 100.0 \mathrm{mmol} / \mathrm{L} \mathrm{PBS}$ ( $\mathrm{pH}$ 9.0) solution containing $20.0 \mathrm{mmol} / \mathrm{L} \mathrm{H}_{2} \mathrm{O}_{2}$. Cyclic voltammetry and ECL were used in the ECL emission process. The voltage, potential range, and scanning rate of the photomultiplier tube (PMT) were $800 \mathrm{~V},-0.3-0.4 \mathrm{~V}$, and $100 \mathrm{mV} / \mathrm{s}$, respectively. CV scanning was performed in $5.0 \mathrm{mmol} / \mathrm{L}\left[\mathrm{Fe}(\mathrm{CN})_{6}\right]^{3-/ 4-}$ containing $0.1 \mathrm{~mol} / \mathrm{L} \mathrm{KCl}$ solution at the potential range of $-0.3-0.6 \mathrm{~V}$. EIS was conducted from $100 \mathrm{mHz}$ to $100 \mathrm{kHz}$ with an alternating current (AC) amplitude of $10 \mathrm{mV}$, which was used to characterize the different modified electrodes. The quenching efficiency of the MIECL sensor was defined as (Io - I)/Io, where Io and I represented the initial values of ECL intensity and the intensity of adding CYF, respectively.

\subsection{Sample Preparation}

The fish samples were purchased from a local supermarket in Ningbo. The fish samples $(5.0 \pm 0.01 \mathrm{~g})$ were homogenized with a homogenizer at $8.0 \times 10^{3} \mathrm{~g}$. Subsequently, $15.0 \mathrm{~mL}$ acetonitrile and $1.5 \mathrm{~g}$ sodium chloride $(\mathrm{NaCL})$ were added. After vortexing for $5 \mathrm{~min}$, the samples were centrifuged at $4.0 \times 10^{3} \mathrm{~g}$ for $10 \mathrm{~min}$, and the procedure was repeated. Then, the supernatants were collected and mixed with $10.0 \mathrm{~mL}$ acetonitrile: n-hexane mixture $(1: 10, \mathrm{v} / \mathrm{v})$ to further remove the fat and pigment contents. After vortexing for $5 \mathrm{~min}$, the acetonitrile layer was separated by centrifugation at $4.0 \times 10^{3} \mathrm{~g}$ for $10 \mathrm{~min}$ and blown to near dryness with nitrogen. Then the residue was diluted to $1.0 \mathrm{~mL}$ with acetonitrile for subsequent analysis.

Seawater samples were obtained from the offshores of Ningbo. The samples were filtered through a microporous nitrocellulose membrane (pore size $0.45 \mu \mathrm{m}$ ). The samples $(5.00 \pm 0.01 \mathrm{~mL})$ were separately placed in $50 \mathrm{~mL}$ polypropylene centrifuge tubes, and the $\mathrm{pH}$ was adjusted to 9.0 for subsequent analysis.

\section{Results and Discussion}

\subsection{Characterization of MIP-CdSe-QDs}

The corresponding sizes and morphologies of MIP-CdSe-QDs and NIP-CdSe-QDs were characterized by scanning electron microscopy (SEM) and TEM. As shown in Figure 1, the fabricated MIP-CdSe-QDs exhibited uniformly-sized microspheres with a diameter of approximately $100 \mathrm{~nm}$. MIP-CdSe-QDs and NIP-CdSe-QDs presented rough surface morphology. No significant difference was found between the surface morphologies of MIP-CdSe-QDs and NIP-CdSe-QDs. In addition, to confirm the successful chemical modification on the QD surface, the Fourier transform infrared (FT-IR) spectroscopy of MIP-CdSe-QDs and NIP-CdSe-QDs were obtained and analyzed (Figure 2). The wide peak at $1057 \mathrm{~cm}^{-1}$ was assigned to the asymmetric stretching vibration of Si-O-Si. Other bands observed at approximately 792 and $463 \mathrm{~cm}^{-1}$ revealed $\mathrm{Si}-\mathrm{O}$ vibrations. The peaks at approximately 2972,3421 , and $1650 \mathrm{~cm}^{-1}$ were consistent with the $\mathrm{C}-\mathrm{H}$ and $\mathrm{N}-\mathrm{H}$ stretching vibrations, indicating that the QDs were successfully embedded with a silica layer, which was formed by the sol-gel hydrolysis and condensation reaction of APTES and TEOS, and that the $-\mathrm{NH}_{2}$ groups of APTES were grafted onto the surface of the QDs [26]. Meanwhile, no significant differences were observed between the FT-IR spectra patterns between MIP-CdSe-QDs and NIP-CdSe-QDs. 

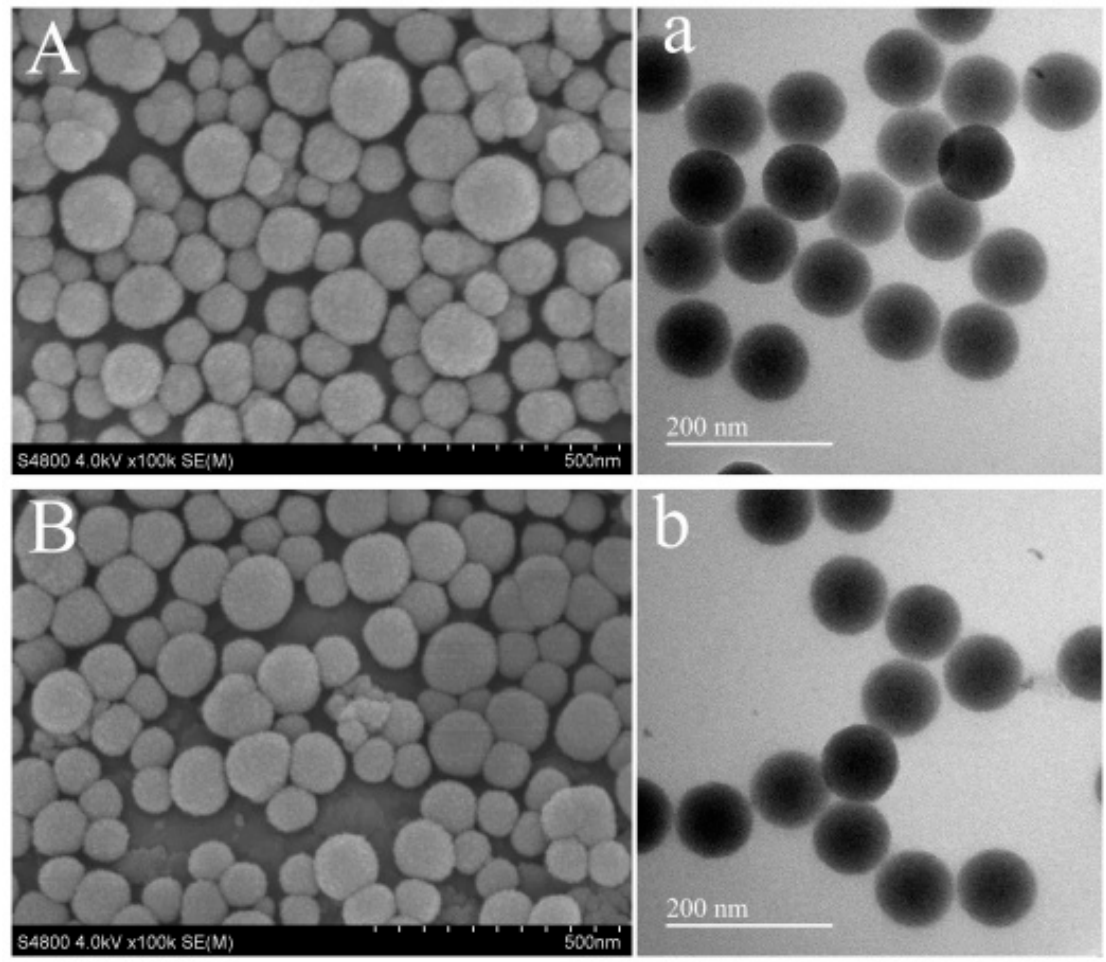

Figure 1. SEM images: (A) MIP-QDs and (B) NIP-QDs. TEM images: (a) MIP-QDs and (b) NIP-QDs.

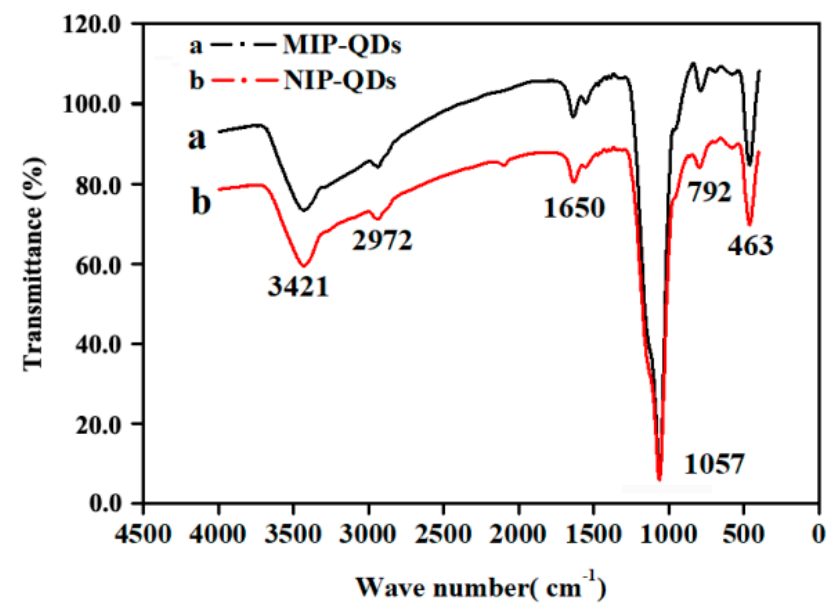

Figure 2. FT-IR spectra of MIP-QDs and NIP-QDs.

\subsection{ECL Behavior and Mechanism of the MIECL Sensor}

The modification of the MIP-QDs on the surface of GCE and the ECL mechanisms of the developed MIECL sensor was explained via the ECL spectra, CV, and EIS. As shown in Figure 3, after the bare GCE was modified with QDs, the ECL intensities (Figure 3A) and reduction-oxidation peak currents (Figure 3B) increased, whereas the electron transfer resistance (Figure 3C) notably decreased. EIS was carried out to characterize the typical impedance spectra. As you can see from Figure 3C, the semicircle diameter in the impedance spectrum equals to the electron transfer resistance, which controls the electron transfer kinetics at the GCE interface. These findings agreed that QDs exhibited good ECL properties and superior conductivity, which could increase their capability for electron transfer [27]. Nevertheless, after the bare GCE was modified with MIP-QDs or NIP-QDs, the ECL intensities and reduction-oxidation peak current evidently decreased compared with those of QDs/GCE, whereas, the electron transfer resistance remarkably increased, thereby indicating that the silica layer on the 
surface of the MIP-QDs/NIP-QDs possessed poor conductivity and hindered electron transfer and exhibited ECL quenching [28].
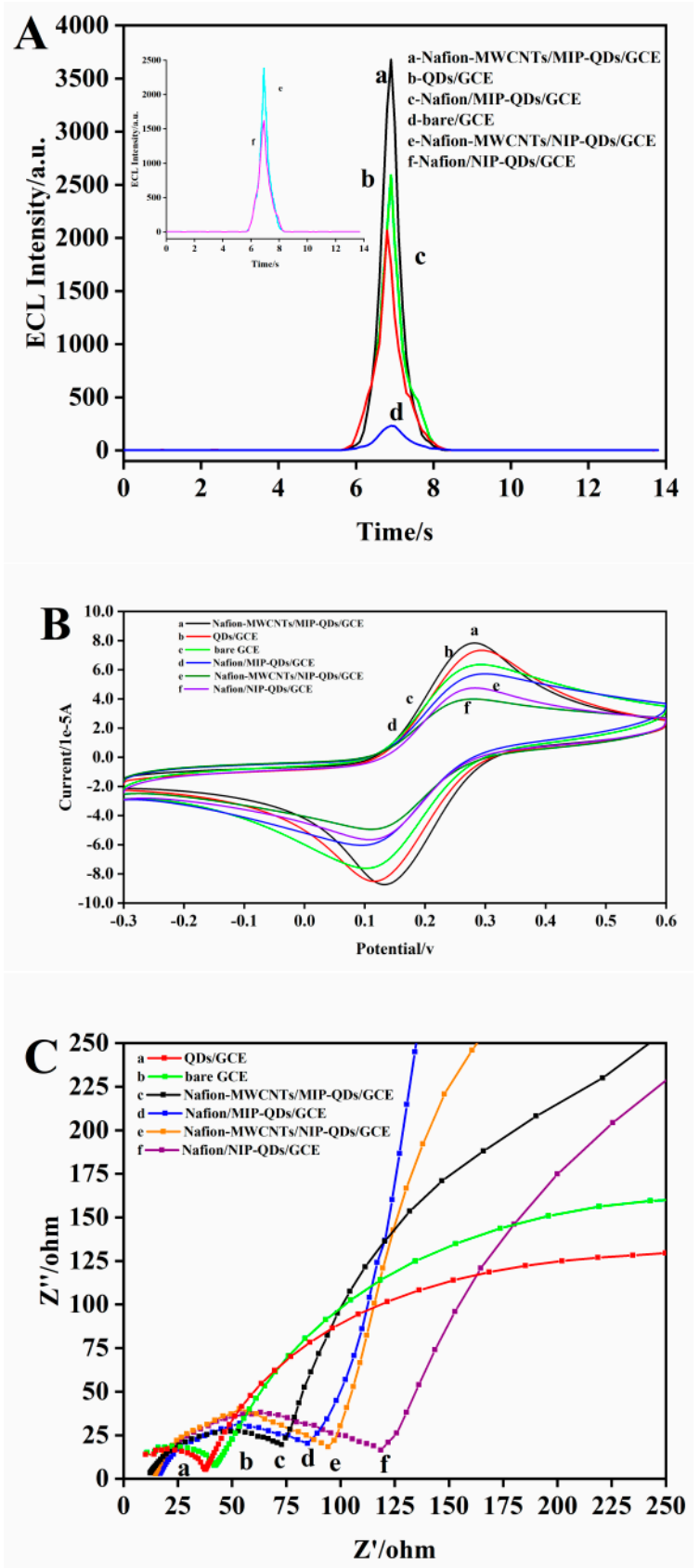

Figure 3. (A) ECL curves, (B) CVs and (C) EIS curves of MIP-QDs/GCE, NIP-QDs/GCE, QDs/GCE, bare GCE. The impedance spectra of frequency range $100 \mathrm{mHz}-100 \mathrm{kHz}$ were recorded under an alternating current (AC) amplitude of $10 \mathrm{mV}$.

As illustrated in Figure 3, although the ECL and reduction-oxidation peak current intensity of MIP-QDs/GCE was lower than that of QDs/GCE, the ECL intensities of MIP-QDs were stronger than those of NIP-QDs. Simultaneously, the MIP-QDs exhibited larger reduction-oxidation peak currents and smaller electron transfer resistance, thereby suggesting that the MIP-QDs possessed higher electrical conductivity compared with NIP-QDs, significantly improving the ECL signals. This property might be ascribed to the numerous selective porous imprinting cavities of the MIP-QDs, which could provide the channels with large surface and pore volume for accelerating electron transfer in the MIECL process [29]. 
In view of the inhibition of ECL by the silica layer on the MIP-QDs surface, MWCNTs were introduced to the MIP-QDs to further improve the ECL intensity and obtain high sensitivity of the developed MIECL sensor. Figure 3 illustrates that the ECL intensities remarkably improved after the introduction of MWCNTs to the MIP-QDs and NIP-QDs/GCE, whereas the reduction-oxidation peak current (Figure 3B) and electron transfer resistance (Figure 3C) increased and decreased, respectively. These findings suggested that MWCNTs could amplify the ECL signal due to their excellent electrical conductivity and good electrochemical activity, thereby accelerating the electron transfer rate [30].

$\mathrm{H}_{2} \mathrm{O}_{2}$ act as a co-reactant and react with individual reduced nanocrystal material or assembly of reduced nanocrystal materials to produce ECL emissions [31]. Furthermore, according to the spectra patterns of the ECL, CV, and EIS of the QDs, MIP-QDs and NIP-QDs observed in this study, the possible ECL mechanisms could be described as below. First, the ground state QDs were electrochemically reduced to negatively charged QDs ${ }^{\mathrm{n} *-}$; second, the QDs radicals directly reacted with $\mathrm{H}_{2} \mathrm{O}_{2}$ to become excited QDs*; finally, the light emitted by the QDs* returned to the ground state. The speculated ECL mechanism is presented as follows:

$$
\begin{gathered}
\text { QDs + ne } \rightarrow \text { QDs }^{\mathrm{n} *-} \\
\mathrm{QDs}^{\mathrm{n} *-}+\mathrm{nH}_{2} \mathrm{O}_{2} \rightarrow \mathrm{nOH}-+\mathrm{QDs}^{*} \\
\mathrm{QDs}^{*} \rightarrow \text { QDs }+\mathrm{hv}
\end{gathered}
$$

Furthermore, as shown in Figure 4, when the MWCNT-Nafion/MIP-QDs/GCE was incubated in $10.0 \mu \mathrm{g} / \mathrm{L}$ CYF solution, the ECL intensities distinctly decreased. The reduction-oxidation peak current (Figure 4B) also decreased, accompanied by the increased electron transfer resistance (Figure 4C). The possible ECL quenching mechanisms of the developed MIECL sensor based on the MIP-QDs are described as follows. When the MIP-QDs/GCE was incubated with CYF, the specific binding of CYF to the imprinted cavities, which were complementary in size, shape, and functional groups to CYF onto the MIP-QDs, blocked the electron transport channel between QDs $/ \mathrm{H}_{2} \mathrm{O}_{2}$ and the GCE, thus causing the specific ECL intensity quenching [32]. 

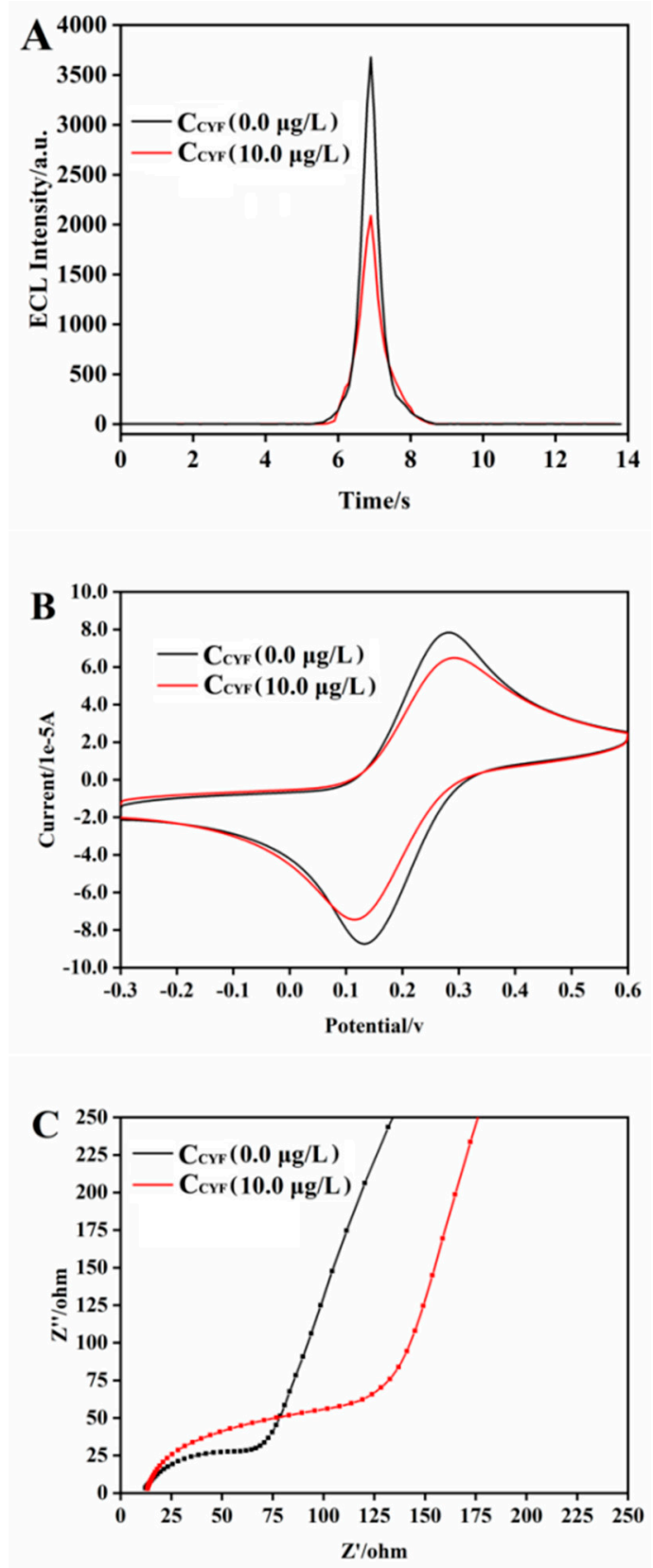

Figure 4. (A) ECL curves, (B) Cyclic voltammograms and (C) EIS curves of Nafion-MWCNTs/MIPQDs/GCE, before and after adding CYF. CYF concentration $\left(\mathrm{C}_{\mathrm{CYF}}\right): 10.0 \mu \mathrm{g} / \mathrm{L}$.

\subsection{Optimization of the MIECL Sensor Conditions}

The effects of parameters, such as $\mathrm{pH}$ and the concentration of the $\mathrm{PBS}, \mathrm{H}_{2} \mathrm{O}_{2}$, and MIP-QDs, on the efficiency of ECL quenching, were assessed. As shown in Figure 5A, the maximum ECL quenching efficiency (45.0\%) of the developed MIECL sensor was achieved at $\mathrm{pH} 9.0$ because the negatively charged substances could promote electron transfer [33]. When the $\mathrm{pH}$ was greater than 9.0, excess anions were loaded on the electrode surface, significantly inhibiting the negative charge of the CdSe-QDs and causing a rapid reduction in quenching efficiency of the MIECL sensor [34].

The effect of PBS concentration on the quenching efficiency of the MIECL sensor was also investigated. As shown in Figure 5B, the quenching efficiency of the MIP-QDs/GCE increased continuously from $40.0 \mathrm{mmol} / \mathrm{L}$ to $100.0 \mathrm{mmol} / \mathrm{L}$. When the PBS concentration exceeded $100.0 \mathrm{mmol} / \mathrm{L}$, the quenching efficiency decreased because the ion concentration of the PBS solution effectively promoted the formation of QDs* and enhanced the quenching efficiency. When the concentration of PBS further increased, 
additional ions aggregated in the polymer cavity, thus hindering the electron transfer on the electrode surface and ultimately resulting in poor quenching efficiency [35].
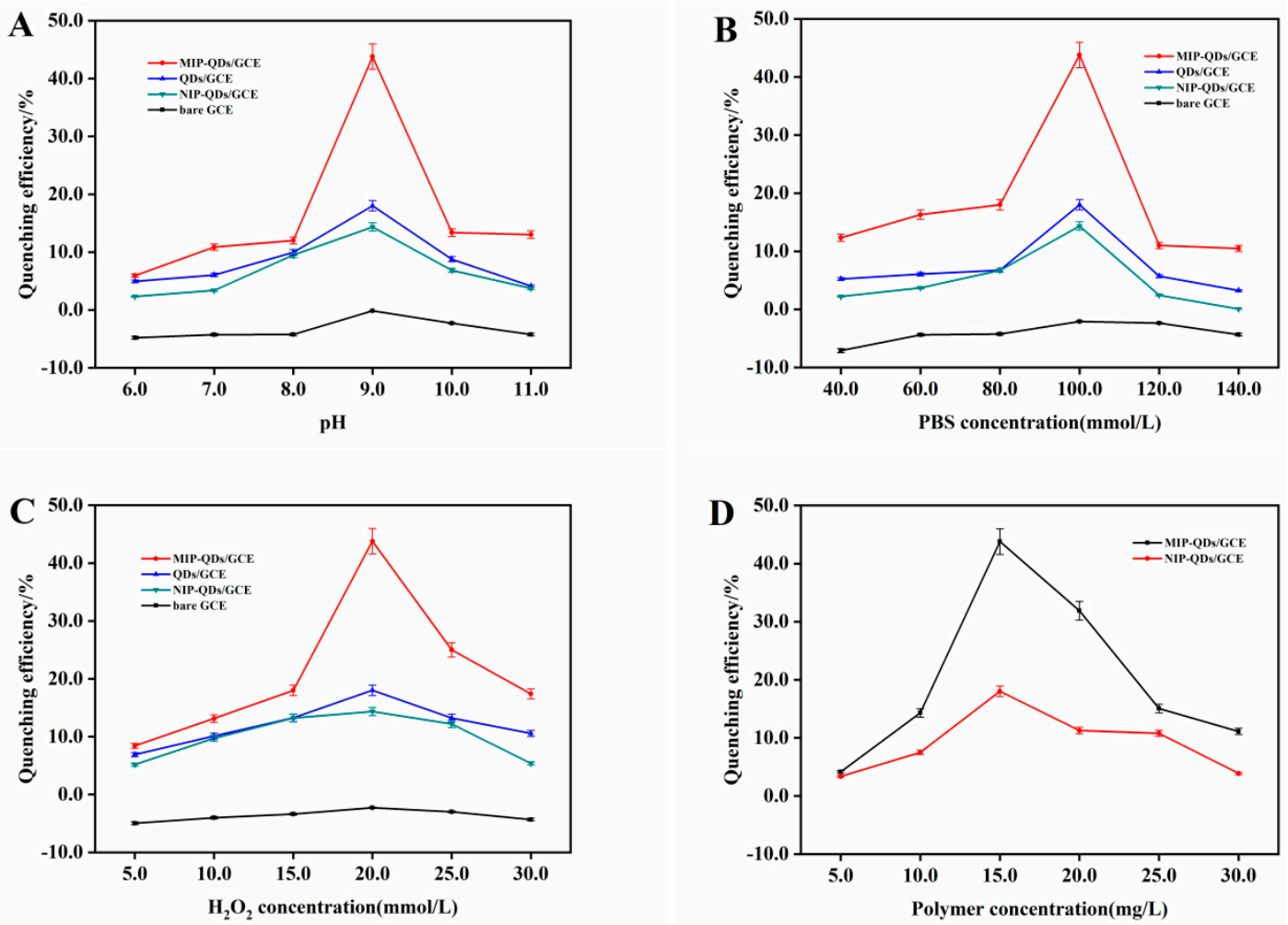

Figure 5. Effects of experimental conditions on the quenching efficiency of MIP-QDs/GCE, NIPQDs/GCE, bare GCE and QDs/GCE: (A) The PBS pH in the ECL cell; (B) The concentration of PBS; (C) The concentration of $\mathrm{H}_{2} \mathrm{O}_{2} ;$ (D) The concentration of polymers.

As the co-reactant, $\mathrm{H}_{2} \mathrm{O}_{2}$ was the most important factor of the developed MIECL sensor in producing ECL signals. As shown in Figure 5C, the quenching efficiency increased with the increase of $\mathrm{H}_{2} \mathrm{O}_{2}$ concentration, reaching the maximum at $20.0 \mathrm{mmol} / \mathrm{L}$. This result was better than obtained with the NIP-QDs/GCE. Meanwhile, excessive $\mathrm{H}_{2} \mathrm{O}_{2}$ easily reacted with the negatively charged cathode, resulting in QDs receiving few electrons, which in turn, inhibited the formation of excited-state QDs* and led to decreased quenching efficiency [36]. Therefore, $20.0 \mathrm{mmol} / \mathrm{L}$ was selected as the optimum concentration of co-reactant $\mathrm{H}_{2} \mathrm{O}_{2}$.

As an identification element, the amounts of the MIP-QDs influenced the stability, selectivity, and durability of the working electrode-modified thin layer [37]. As presented in Figure 5D, as the concentration increased from $5.0 \mathrm{mg} / \mathrm{L}$ to $15.0 \mathrm{mg} / \mathrm{L}$, the quenching efficiency of the developed MIECL sensor continually increased until $45.0 \%$, which was better than that of MWCNTs-Nafion/NIP-QDs/GCE. Such an increase in quenching efficiency may be caused by the good conductivity of the CdSe-QDs, which remarkably enhanced the mobility of system ions on the surface of the MIP-QDs/GCE, resulting in high quenching efficiency of the developed MIECL sensor for target molecules [38]. However, when the concentration of the MIP-QDs exceeded $15.0 \mathrm{mg} / \mathrm{L}$, the quenching efficiency of the developed MIECL sensor decreased gradually. These results suggested that the electron transfer resistance conferred by the silica layers upon the surface of the MIP-QDs played a dominant role when excess amounts of MIP-QDs were coated onto the GCE, eventually decreasing quenching efficiency. Hence, $15.0 \mathrm{mg} / \mathrm{mL}$ MIP-QDs were selected in the fabrication the MIECL sensor.

We observed that the MIP-QDs/GCE (45.0\%) exhibited stronger quenching efficiency for CYF than NIP-QDs/GCE (13.0\%) within the parameters and scopes of this study. This result further proved that the imprinted silica layers were successfully coated onto the surface of the QDs. Moreover, the specific 
recognition of imprinting cavities on the surface of the MIP-QDs toward CYF played an important role in the ECL quenching of the developed MIECL sensor.

\subsection{Selectivity Evaluation of the Developed MICEL Sensor}

MIPs possess excellent specificity and selectivity, and template molecules can specifically bind to recognition sites onto the surface of MIPs. Under optimal conditions, selective experiments were carried out to evaluate the recognition capability of the proposed MIECL sensor. Figure 6A showed that the developed MIECL sensor exhibited stronger ECL quenching than NIP-QDs for CYF. The strongest ECL quenching of CYF to the MIP-QDs/GCE was obtained compared with those of its structural analogs, such as (a) BIF, (b) DEL, (c) CYP, and (d) FEN (Figure 7). These results indicated that the specific imprinting recognition sites, with complementary spatial structures and binding sites for CYF, were anchored onto the surface of the MIP-QDs. Meanwhile, the similar low level ECL quenching capability of the NIP-QDs/GCE to CYF and its analogs were detected, thus indicating that no specific recognition coating was fabricated onto the surface of the NIP-QDs/GCE. Furthermore, the selectivity of the MIP-QDs/GCE was confirmed by competitive ECL quenching experiments. As shown in Figure 6B, when the two-fold concentrations of its analogs were mixed to the $10.0 \mu \mathrm{g} / \mathrm{L} \mathrm{CYF}$, there was no significant change in the ECL intensity of the MIP-QDs/GCE, indicating that the MIECL sensor exhibited high selectivity in CYF determination. These results demonstrated that the developed MIP-QDs exhibited excellent selectivity and ECL quenching capability to CYF; furthermore, the specific binding of imprinting cavities to CYF is the major dominating force in the ECL quenching response.
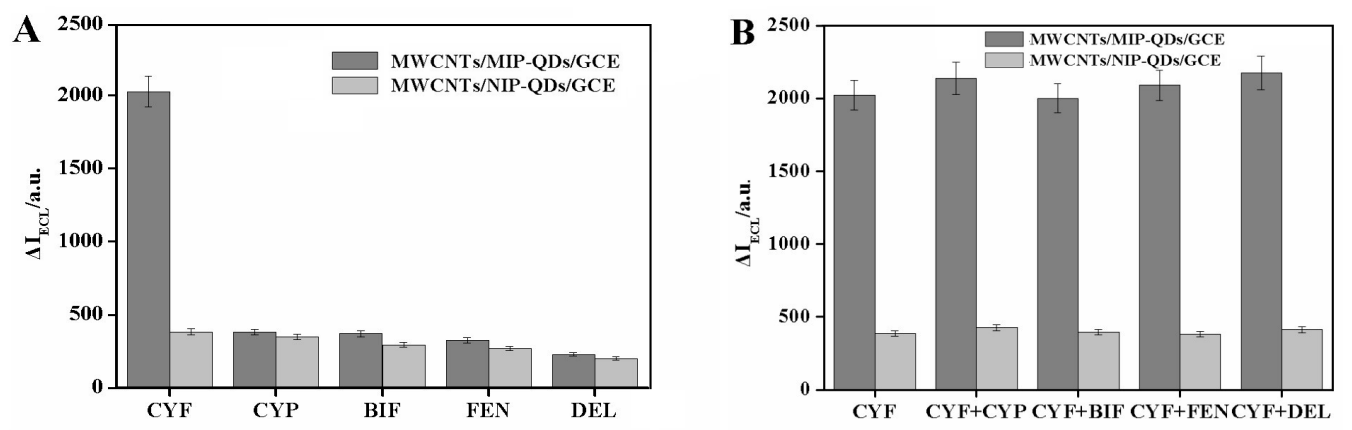

Figure 6. (A) Selectivity of the MIECL sensor to CYF and its structural analogs (CYP, BIF, FEN, and DEL) at the same concentration; (B) Competitive tests of the MIECL sensor to CYF and its analogues (CYP, BIF, FEN, DEL,). Two-fold concentrations of these interferents were added to $10.0 \mu \mathrm{g} / \mathrm{L} \mathrm{CYF}$.

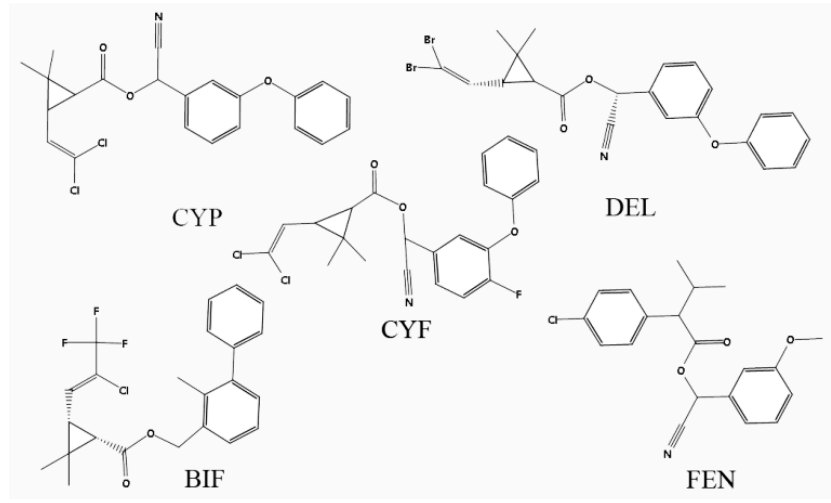

Figure 7. The Chemical structure of CYF and its structural analog.

\subsection{Application of the MIECL Sensor in the Fish and Seawater Samples}

The practical application of the developed MIECL sensor based on the Nafion-MWCNTs/MIPQDs/GCE was validated in terms of linearity, sensitivity, stability, reproducibility, accuracy, and precision under optimal conditions. 
First, we investigated the linear relationship between the CYF concentration and ECL response. As observed in Figure 8A, the ECL intensity decreased gradually as the CYF concentration increased. A good linear relationship between the ECL intensity and the logarithm of CYF concentration was obtained within the CYF concentrations ranging from $0.2 \mu \mathrm{g} / \mathrm{L}$ to $1.0 \times 10^{3} \mu \mathrm{g} / \mathrm{L}$ with a determination coefficient $\left(\mathrm{R}^{2}\right)$ of $0.9983(\mathrm{n}=6$, Figure $8 \mathrm{~B})$. The calibration curve was described as follows: $\mathrm{I}=-834.96$ $\log$ CCYF -2247.9. The calculated limit of detection (LOD) was $0.05 \mu \mathrm{g} / \mathrm{L}(\mathrm{S} / \mathrm{N}=3)$. Meanwhile, as shown in Figure 9, the reduction-oxidation peak current of the MIP-QDs/GCE was sequentially decreased in the range of $0.2 \mu \mathrm{g} / \mathrm{L}$ to $1.0 \times 10^{3} \mu \mathrm{g} / \mathrm{L}$. Correspondingly, the electron transfer resistance of MIP-QDs sequentially increased, further demonstrating that the decreased ECL strength of the developed MIECL sensor was ascribed to the blockage electron transfer channel on the surface of MIP-QDs after CYF rebinding $[37,39]$.
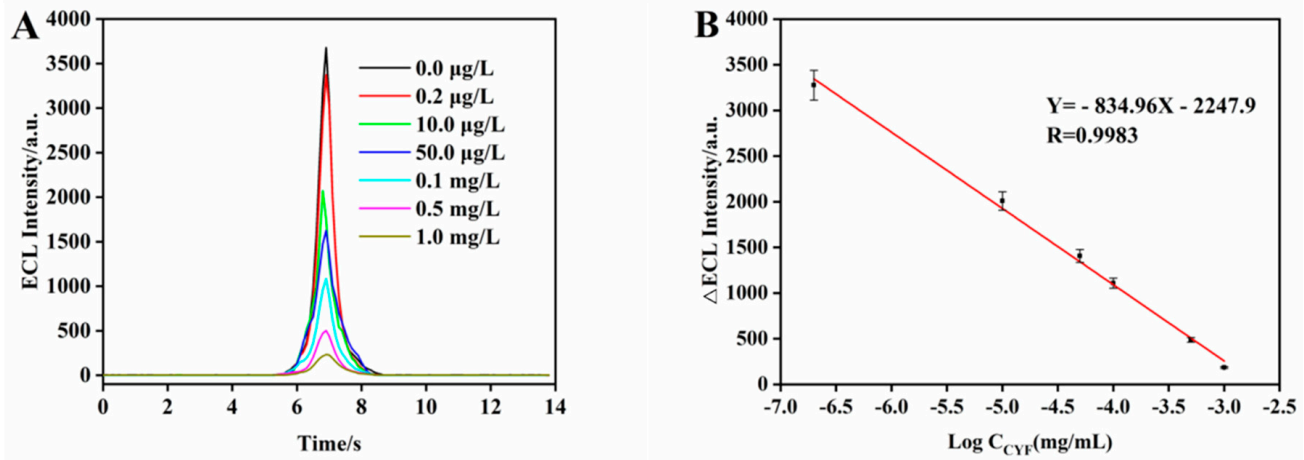

Figure 8. (A) ECL responses of the proposed MIECL sensor in the presence of various CYF concentrations $(0.2 \mu \mathrm{g} / \mathrm{L}, 10.0 \mu \mathrm{g} / \mathrm{L}, 50.0 \mu \mathrm{g} / \mathrm{L}, 0.1 \mathrm{mg} / \mathrm{L}, 0.5 \mathrm{mg} / \mathrm{L}$, and $1.0 \mathrm{mg} / \mathrm{L}) ;(\mathbf{B})$ calibration curves of the MIECL sensor for CYF determination.
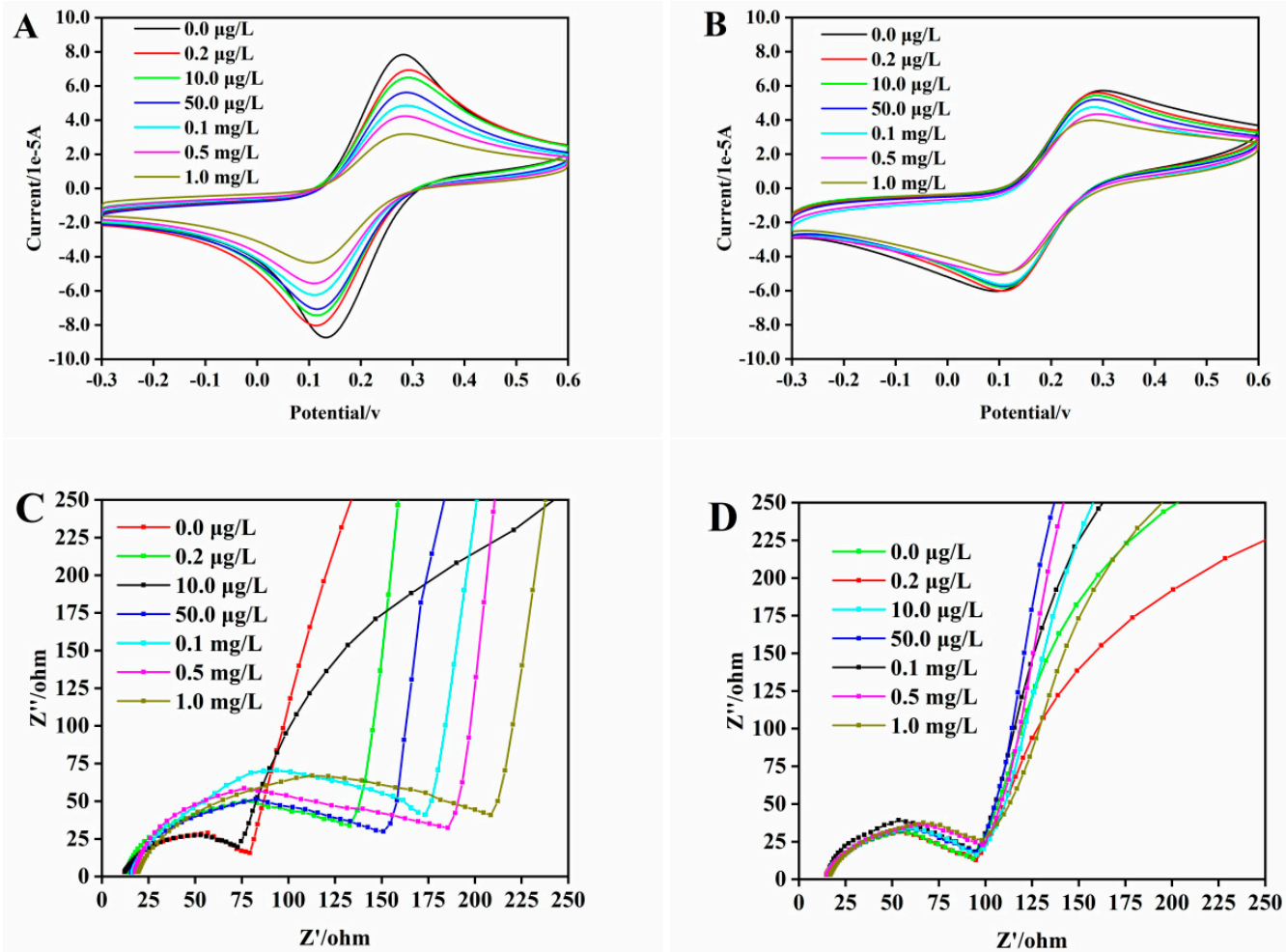

Figure 9. (A) CVs of MIP-QDs/GCE; (B) NIP-QDs/GCE; (C) EIS curves of MIP-QDs/GCE; (D)NIP-QDs/GCE responses of the proposed MIECL sensor in the presence of various CYF concentrations $(0.2 \mu \mathrm{g} / \mathrm{L}, 10.0 \mu \mathrm{g} / \mathrm{L}$, $50.0 \mu \mathrm{g} / \mathrm{L}, 0.1 \mathrm{mg} / \mathrm{L}, 0.5 \mathrm{mg} / \mathrm{L}, 1.0 \mathrm{mg} / \mathrm{L})$ in $5.0 \mathrm{mmol} / \mathrm{L}\left[\mathrm{Fe}(\mathrm{CN})_{6}\right]^{3-/ 4-}$ containing $0.1 \mathrm{~mol} / \mathrm{L} \mathrm{KCL}$ solution. 
Stability and repeatability were considered non-negligible features for evaluating the performance of the MIECL sensor. Figure 10A showed the ECL strength of the MIECL sensor under 12 cycles of continuous cyclic potential scanning and the $2.7 \%$ relative standard deviation (RSD) of the ECL signal $(10.0 \mu \mathrm{g} / \mathrm{L}$ of CYF), indicating excellent stability of the developed MIECL sensor. At the same time, long-term storage stability was evaluated by monitoring the ECL strength of the developed MIECL sensor. As illustrated in Figure 10B, the ECL strength of the developed sensor was maintained at 85.3\% of the original strength after 2 weeks of storage in a refrigerator at $4{ }^{\circ} \mathrm{C}$, thus indicating the satisfactory reproducibility and good stability of the developed MIECL sensor. The above results demonstrated the excellent application potential of the developed MIECL sensor in field detection.
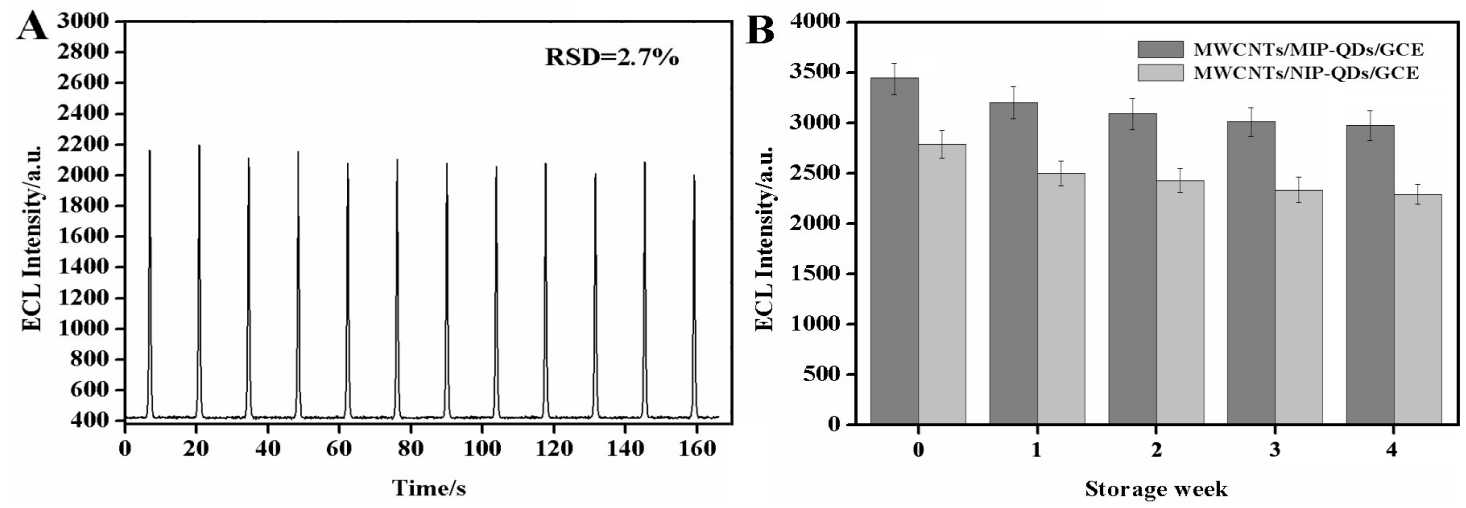

Figure 10. (A) ECL stability of the MIECL sensor with $10.0 \mu \mathrm{g} / \mathrm{L}$ CYF in PBS (100.0 mmol/L, pH 9.0) containing $20.0 \mathrm{mmol} / \mathrm{L} \mathrm{H}_{2} \mathrm{O}_{2}$; (B) Storing stability of the sensor for 0-4 weeks.

The developed MIECL sensor was applied to the determination of different CYF concentrations in fish and seawater samples. As summarized in Table 1, the recoveries of CYF in fish samples at three spiked concentrations $(10.0,20.0$, and $50.0 \mu \mathrm{g} / \mathrm{kg}$ ) ranged from $93.2 \%$ to $98.6 \%$ with RSDs below $3.6 \%$. The LOD, which was defined as the CYF concentration that could quench three times the standard deviation of the blank sample ECL signal, was $0.22 \mu \mathrm{g} / \mathrm{kg}$. The recoveries obtained from seawater samples ranged from $86.0 \%$ to $98.4 \%$, with RSDs below $4.1 \%$, and LOD was $0.11 \mu \mathrm{g} / \mathrm{L}$, at concentrations of 1.0, 2.0, and $5.0 \mu \mathrm{g} / \mathrm{L}$. These results indicated the excellent practical application of the MIECL sensor based on the MIP-QDs for accurate CYF determination.

Table 1. Results of ECL measurements of CYF content in real samples using the proposed MIECLS.

\begin{tabular}{ccccc}
\hline Sample & Added $(\boldsymbol{\mu g} / \mathbf{k g}, \mathbf{L})$ & Found $(\boldsymbol{\mu g} / \mathbf{k g}, \mathbf{L})$ & RSD $(\%)(\mathbf{n}=\mathbf{3})$ & Recovery $(\%)(\mathbf{n}=\mathbf{3})$ \\
\hline \multirow{3}{*}{ Fish } & 10.0 & 9.32 & 3.6 & 93.2 \\
& 20.0 & 19.72 & 3.2 & 98.6 \\
& 50.0 & 47.87 & 2.2 & 95.7 \\
\multirow{3}{*}{ Seawater } & 1.0 & 0.86 & 1.5 & 86.0 \\
& 2.0 & 1.76 & 2.5 & 88.0 \\
& 5.0 & 4.92 & 4.1 & 98.4 \\
\hline
\end{tabular}

Finally, the developed MIECL sensor in this study demonstrated excellent performance with better sensitivity, wide linear range, accuracy, precision, and reproducibility compared to other detection methods (Table 2). 
Table 2. Comparison of this method with other methods reported in the literatures.

\begin{tabular}{|c|c|c|c|c|c|}
\hline Detection Method & Target Object & $\begin{array}{l}\text { Linear Range } \\
(\mu \mathrm{g} / \mathrm{kg}, \mathrm{L})\end{array}$ & LOD $(\mu \mathrm{g} / \mathrm{kg}, \mathrm{L})$ & Recovery (\%) & Reference \\
\hline $\mathrm{SiO}_{2}$-MPTMS @FMIPs & Beta-Cyfluthrin & $4.6-36.0$ & 4.55 & $103.8-111.8$ & [40] \\
\hline $\begin{array}{l}\text { Inorganic-organic } \\
\text { MIP-coated QDs }\end{array}$ & Cyphenothrin & $37.5-3.0 \times 10^{4}$ & 3.40 & $88.5-97.1$ & [41] \\
\hline MIPs-OVDAC/CdTe QDs & $\lambda$-Cyhalothrin & $45.0-7.2 \times 10^{3}$ & 13.5 & $97.3-105.5$ & [42] \\
\hline MIP on FeSe QDs & Cyfluthrin & $10.0-2.0 \times 10^{2}$ & 1.00 & $88.0-113.9$ & [24] \\
\hline Dy(III)@SiO2@MIPs & $\lambda$-cyhalothrin & $4.5 \times 10^{3}-4.5 \times 10^{5}$ & 719.7 & $102.7-107.9$ & [43] \\
\hline $\begin{array}{c}\text { Nafion-MWCNTs/MIP-CdSe } \\
\text { QDs }\end{array}$ & Cyfluthrin & $0.2-1.0 \times 10^{3}$ & 0.05 & $86.0-98.6$ & This work \\
\hline
\end{tabular}

\section{Conclusions}

The MIECL sensor based on the MIP-QDs was fabricated for the first time for CYF determination in seawater and fish samples. The MIECL mechanisms based on the MIP-QDs with $\mathrm{H}_{2} \mathrm{O}_{2}$ as co-reactant were explained, and its introduction into the Nafion ion exchange membrane significantly enhanced the ECL signal of the MIECL sensor, which is due to the excellent electrical conductivity of MWCNTs. Apart from its successful application to CYF determination in fish and seawater samples, the developed MIECL sensor showed good sensitivity, selectivity, stability, and linearity. The excellent performance of the MIECL sensor provides a potential strategy for the sensitive and selective determination of CYF residues in aquaculture biology and environment samples.

Author Contributions: Methodology, validation, and writing, J.X.; Writing, visualization, and investigation, R.Z.; Data curation and writing, C.L.; Validation and writing-original draft preparation, A.S.; Data curation and supervision, J.C.; Visualization, writing, Z.Z.; Conceptualization, data curation, and writing-review and editing, X.S. All authors have read and agreed to the published version of the manuscript.

Funding: This research was funded by the National Natural Science Foundation of China (31772856), the Zhejiang Provincial Major Science and Technology Project (2020C02023), the Natural Science Foundation of Ningbo (2018A610065), the Technology Innovation Team of Ningbo city (2015C110018), and the K.C. Wong Magna Fund in Ningbo University.

Conflicts of Interest: The authors declare no conflict of interest.

\section{References}

1. Hu, G.P.; Zhao, Y.; Song, F.Q.; Liu, B. Isolation, identification and cyfluthrin-degrading potential of a novel Lysinibacillus sphaericus strain, FLQ-11-1. Res. Microbiol. 2014, 165, 110-118. [CrossRef] [PubMed]

2. Lao, W.; Tiefenthaler, L.; Greenstein, D.J.; Maruya, K.A.; Bay, S.M.; Ritter, K.; Schiff, K. Pyrethroids in southern california coastal sediments. Environ. Toxicol. Chem. 2012, 31, 1649-1656. [CrossRef] [PubMed]

3. Hughes, M.F.; Ross, D.G.; Starr, J.M.; Scollon, E.J.; Wolansky, M.J.; Crofton, K.M.; Devito, M.J. Environmentally relevant pyrethroid mixtures: A study on the correlation of blood and brain concentrations of a mixture of pyrethroid insecticides to motor activity in the rat. Toxicology 2016, 359, 19-28. [CrossRef] [PubMed]

4. Mehmet, Y.; Eyyup, R.; Mustafa, C. The effects of cyfluthrin on some biomarkers in the liver and kidney of Wistar rats. Environ. Sci. Pollut. Res. 2015, 22, 4747-4752.

5. Brander, S.M.; Gabler, M.K.; Fowler, N.L.; Connon, R.E.; Schlenk, D. Pyrethroid pesticides as endocrine disruptors: Molecular mechanisms in vertebrates with a focus on fishes. Environ. Sci. Technol. 2016, 50, 8977-8992. [CrossRef] [PubMed]

6. Beltran, J.; Peruga, A.; Pitarch, E.; Lopez, F.J.; Hernandez, F. Application of solid-phase microextraction for the determination of pyrethroid residues in vegetable samples by GC-MS. Anal. Bioanal. Chem. 2003, 376, 502-511. [CrossRef] [PubMed]

7. $\quad$ Oliveira, L.G.; Kurz, M.H.S.; Guimarães, M.C.M.; Martins, M.L.; Prestes, O.D.; Zanella, R.; Ribeiro, J.N.S.; Gonçalves, F.F. Development and validation of a method for the analysis of pyrethroid residues in fish using GC-MS. Food Chem. 2019, 297, 124944. [CrossRef]

8. Amjad, A.; Randhawa, M.A.; Javed, M.S.; Muhammad, Z.; Ashraf, M.; Ahmad, Z.; Murtaza, S. Dietary intake assessment of pyrethroid residues from okra and eggplant grown in peri-urban areas of Punjab, Pakistan. Environ. Sci. Pollut. Res. 2019, 26, 1-9. [CrossRef] 
9. Jabot, C.; Fieu, M.; Giroud, B.; Buleté, A.; Casabianca, H.; Vulliet, E. Trace-level determination of pyrethroid, neonicotinoid and carboxamide pesticides in beeswax using dispersive solid-phase extraction followed by ultra-high-performance liquid chromatography-tandem mass spectrometry. Int. J. Environ. Anal. Chem. 2015, 95, 240-257. [CrossRef]

10. Kaushik, A.; Solanki, P.R.; Ansari, A.A.; Malhotra, B.D.; Ahmad, S. Iron oxide-chitosan hybrid nanobiocomposite based nucleic acid sensor for pyrethroid detection. Biochem. Eng. J. 2009, 46, 132-140. [CrossRef]

11. Babamiri, B.; Salimi, A.; Hallaj, R. A molecularly imprinted electrochemiluminescence sensor for ultrasensitive HIV-1 gene detection using EuS nanocrystals as luminophore. Biosens. Bioelectron. 2018, 117, 332-339. [CrossRef] [PubMed]

12. Babamiri, B.; Salimi, A.; Hallaj, R.; Hasanzadeh, M. Nickel nanoclusters as a novel emitter for molecularly imprinted electrochemiluminescence based sensor toward nanomolar detection of creatinine. Biosens. Bioelectron. 2018, 107, 272-279. [CrossRef] [PubMed]

13. Xu, H.; Zhu, X.; Wang, J.; Lin, Z.; Chen, G. Electrochemiluminescent functional nucleic acids-based sensors for food analysis. Luminescence 2019, 34, 308-315. [CrossRef] [PubMed]

14. Dennany, L.; Gerlach, M.; O'Carroll, S.; Keyes, T.E.; Forster, R.J.; Bertoncello, P. Electrochemiluminescence (ECL) sensing properties of water soluble core-shell CdSe/ZnS quantum dots/Nafion composite films. J. Mater. Chem. 2011, 21, 13984-13990. [CrossRef]

15. Miao, W.J.; Choi, J.P.; Bard, A.J. Electrogenerated chemiluminescence 69: The Tris(2,2'-bipyridine)ruthenium(II), $\left(\mathrm{Ru}(\mathrm{bpy})^{32+}\right) /$ Tri-n-propylamine $(\mathrm{TPrA})$ system revisited A new route involving TPrA $\bullet+$ Cation Radicals. J. Am. Chem. Soc. 2002, 124, 14478-14485. [CrossRef] [PubMed]

16. Jin, X.; Fang, G.; Pan, M.; Yang, Y.; Bai, X.; Wang, S. A molecularly imprinted electrochemiluminescence sensor based on upconversion nanoparticles enhanced by electrodeposited rGO for selective and ultrasensitive detection of clenbuterol. Biosens. Bioelectron. 2017, 102, 357-364. [CrossRef]

17. Zhai, Q.; Li, J.; Wang, E. Recent advances based on nanomaterials as electrochemiluminescence probes for the fabrication of sensors. ChemElectroChem 2017, 4, 1639-1650. [CrossRef]

18. Ding, Z.; Quinn, B.M.; Haram, S.K.; Pell, L.E.; Korgel, B.A.; Bard, A.J. Electrochemistry and electrogenerated chemiluminescence from silicon nanocrystal quantum dots. Science 2002, 296, 1293-1297. [CrossRef]

19. Valenti, G.; Rampazzo, E.; Kesarkar, S.; Genovese, D.; Fiorani, A.; Zanut, A.; Palomba, F.; Marcaccio, M.; Paolucci, F.; Prodi, L. Electrogenerated chemiluminescence from metal complexes-based nanoparticles for highly sensitive sensors applications. Coordin. Chem. Rev. 2018, 367, 65-81. [CrossRef]

20. Chullasat, K.; Nurerk, P.; Kanatharana, P.; Davis, F.; Bunkoed, O. A facile optosensing protocol based on molecularly imprinted polymer coated on CdTe quantum dots for highly sensitive and selective amoxicillin detection. Sens. Actuator B Chem. 2018, 254, 255-263. [CrossRef]

21. Hassanzadeh, J.; Khataee, A.; Oskoei, Y.M.; Fattahi, H.; Bagheri, N. Selective chemiluminescence method for the determination of trinitrotoluene based on molecularly imprinted polymer-capped $\mathrm{ZnO}$ quantum dots. New J. Chem. 2017, 41, 10659-10667. [CrossRef]

22. Carrara, S.; Nguyen, P.; D'Alton, L.; Hogan, C.F. Electrochemiluminescence energy transfer in mixed iridium-based redox copolymers immobilised as nanoparticles. Electrochim. Acta 2019, 313, 397-402. [CrossRef]

23. Li, S.; Tao, H.; Li, J. Molecularly imprinted electrochemical luminescence sensor based on enzymatic amplification for ultratrace isoproturon determination. Electroanalysis 2012, 24, 1664-1670. [CrossRef]

24. Li, X.J.; Jiao, H.F.; Shi, X.Z.; Sun, A.L.; Wang, X.J.; Chai, J.Y.; Li, D.X.; Chen, J. Development and application of a novel fluorescent nanosensor based on FeSe quantum dots embedded silica molecularly imprinted polymer for the rapid optosensing of cyfluthrin. Biosens. Bioelectron. 2017, 99, 268-273. [CrossRef] [PubMed]

25. Cai, W.S.; Yan, J.B.; Hussin, T.; Liu, J.Y. Nafion-AC-based asymmetric capacitive deionization. Electrochim. Acta 2017, 225, 407-415. [CrossRef]

26. Xiao, T.T.; Shi, X.Z.; Jiao, H.F.; Sun, A.L.; Ding, H.; Zhang, R.R.; Pan, D.D.; Li, D.X.; Chen, J. Selective and sensitive determination of cypermethrin in fish via enzyme-linked immunosorbent assay-like method based on molecularly imprinted artificial antibody-quantum dot optosensing materials. Biosens. Bioelectron. 2016, 75, 34-40. [CrossRef]

27. Zhao, W.W.; Wang, J.; Zhu, Y.C.; Xu, J.J.; Chen, H.Y. Quantum Dots: Electrochemiluminescent and photoelectrochemical bioanalysis. Anal. Chem. 2015, 87, 9520-9531. [CrossRef] 
28. Wang, R.; Yan, K.; Wang, F.; Zhang, J.R. A highly sensitive photoelectrochemical sensor for 4-aminophenol based on CdS-graphene nanocomposites and molecularly imprinted polypyrrole. Electrochim. Acta 2014, 121, 102-108. [CrossRef]

29. Lian, H.T.; Liu, B.; Chen, Y.P.; Sun, X.Y. A urea electrochemical sensor based on molecularly imprinted chitosan film doping with CdS quantum dots. Anal. Biochem. 2012, 426, 40-46. [CrossRef]

30. Yang, X.; Yuan, R.; Chai, Y.; Zhuo, Y.; Mao, L.; Liu, Z.; Su, H.; Yuan, S. Electrochemiluminescence sensor based on multiwalled carbon nanotubes doped polyvinyl butyral film containing $\mathrm{Ru}(\mathrm{bpy})_{3}{ }^{2+}$ as chemiluminescence reagent. Electroanalysis 2009, 21, 1636-1640. [CrossRef]

31. Zou, G.Z.; Ju, H.X. Electrogenerated chemiluminescence from a CdSe nanocrystal film and its sensing application in aqueous solution. Anal. Chem. 2004, 76, 6871-6876. [CrossRef] [PubMed]

32. Alizadeh, T.; Amjadi, S. A tryptophan assay based on the glassy carbon electrode modified with a nano-sized tryptophan-imprinted polymer and multi-walled carbon nanotubes. New J. Chem. 2017, 41, 4493-4502. [CrossRef]

33. Xia, H.Q.; Kitazumi, Y.; Shirai, O.; Kano, K. Enhanced direct electron transfer-type bioelectrocatalysis of bilirubin oxidase on negatively charged aromatic compound-modified carbon electrode. J. Electroanal. Chem. 2016, 763, 104-109. [CrossRef]

34. Yang, Y.; Liu, Q.; Liu, X.P.; Liu, P.Z.; Mao, C.J.; Niu, H.L.; Jin, B.K.; Zhang, S.Y. Multifunctional reduced graphene oxide ( $\mathrm{RGO}) / \mathrm{Fe}_{3} \mathrm{O}_{4} / \mathrm{CdSe}$ nanocomposite for electrochemiluminescence immunosensor. Electrochim. Acta 2016, 190, 948-955. [CrossRef]

35. Noipa, T.; Martwiset, S.; Butwong, N.; Tuntulani, T.; Ngeontae, W. Enhancement of the fluorescence quenching efficiency of DPPH• on colloidal nanocrystalline quantum dots in aqueous micelles. J. Fluoresc. 2011, 21, 1941-1949. [CrossRef]

36. Mo, G.; He, X.; Zhou, C.; Ya, D.; Feng, J.; Yu, C.; Deng, B. Sensitive detection of hydroquinone based on electrochemiluminescence energy transfer between the exited ZnSe quantum dots and benzoquinone. Sens. Actuator B Chem. 2018, 266, 784-792. [CrossRef]

37. Alizadeh, T.; Zare, M.; Ganjali, M.R.; Norouzi, P.; Tavana, B. A new molecularly imprinted polymer (MIP)-based electrochemical sensor for monitoring 2,4,6-trinitrotoluene (TNT) in natural waters and soil samples. Biosens. Bioelectron. 2010, 25, 1166-1172. [CrossRef]

38. Cao, Z.; Gu, Z.; Zeng, J.L.; Liu, J.H.; Deng, Q.; Fan, J.B.; Xiang, J.N. A novel fluorescent probe for copper ions based on polymer-modified CdSe/CdS core/shell quantum dots. Anal. Sci. 2011, 27, 643. [CrossRef]

39. Yang, Y.; Fang, G.; Wang, X.; Zhang, F.; Liu, J.; Zheng, W.; Wang, S. Electrochemiluminescent graphene quantum dots enhanced by $\mathrm{MoS}_{2}$ as sensing platform: A novel molecularly imprinted electrochemiluminescence sensor for 2-methyl-4-chlorophenoxyacetic acid assay. Electrochim. Acta 2017, 228, 107-113. [CrossRef]

40. Qiu, H.; Gao, L.; Wang, J.; Pan, J.; Yan, Y.; Zhang, X. A precise and efficient detection of Beta-Cyfluthrin via fluorescent molecularly imprinted polymers with ally fluorescein as functional monomer in agricultural products. Food Chem. 2017, 217, 620-627. [CrossRef]

41. Ren, X.H.; Chen, L.G. Quantum dots coated with molecularly imprinted polymer as fluorescence probe for detection of cyphenothrin. Biosens. Bioelectron. 2015, 64, 182-188. [CrossRef] [PubMed]

42. Wei, X.; Hao, T.F.; Xu, Y.Q.; Lu, K.; Li, H.J.; Yan, Y.S.; Zhou, Z.P. Facile polymerizable surfactant inspired synthesis of fluorescent molecularly imprinted composite sensor via aqueous CdTe quantum dots for highly selective detection of $\lambda$-cyhalothrin. Sens. Actuator B Chem. 2016, 224, 315-324. [CrossRef]

43. Zheng, X.; Zhang, F.; Liu, E.; Shi, W.; Yan, Y. A lanthanide complex-based molecularly imprinted luminescence probe for rapid and selective determination of $\lambda$-cyhalothrin in the environment. New J. Chem. 2016, 40, 6141-6147. [CrossRef]

(C) 2020 by the authors. Licensee MDPI, Basel, Switzerland. This article is an open access article distributed under the terms and conditions of the Creative Commons Attribution (CC BY) license (http://creativecommons.org/licenses/by/4.0/). 